OPEN ACCESS

Edited by:

Die Wang,

Hudson Institute of Medical Research,

Australia

Reviewed by:

Jafar Rezaie,

Urmia University of Medical Sciences,

Katie Meehan

The Chinese University of Hong Kong,

China

Suna Zhou,

Wenzhou Medical University, China

*Correspondence:

Peng Li

lipeng@ccum.edu.cn

Guiping Zhao

zhaoguiping@ccmu.edu.cn

${ }^{\dagger}$ These authors have contributed equally to this work and share first authorship

Specialty section: This article was submitted to Cancer Genetics, a section of the journal Frontiers in Oncology

Received: 29 June 2021 Accepted: 09 August 2021 Published: 30 August 2021

Citation: Zhao Z, Yang S, Zhou A, Li X, Fang R, Zhang S, Zhao G and LiP (2021) Small Extracellular Vesicles in the Development, Diagnosis, and Possible Therapeutic Application of Esophageal Squamous Cell Carcinoma.

Front. Oncol. 11:732702. doi: 10.3389/fonc.2021.732702

\section{Small Extracellular Vesicles in the Development, Diagnosis, and Possible Therapeutic Application of Esophageal Squamous Cell Carcinoma}

\author{
Zheng Zhao ${ }^{\dagger}$, Shuyue Yang ${ }^{\dagger}$, Anni Zhou, Xiao Li, Rui Fang, Shutian Zhang, \\ Guiping Zhao * and Peng $\mathrm{Li}^{\text {* }}$ \\ Department of Gastroenterology, Beijing Friendship Hospital, Capital Medical University, Beijing, China
}

Esophageal squamous cell carcinoma (ESCC) persists among the most lethal and broadspreading malignancies in China. The exosome is a kind of extracellular vesicle (EV) from about 30 to $200 \mathrm{~nm}$ in diameter, contributing to the transfer of specific functional molecules, such as metabolites, proteins, lipids, and nucleic acids. The paramount role of exosomes in the formation and development of ESCC, which relies on promoting intercellular communication in the tumor microenvironment (TME), is manifested with immense amounts. Tumor-derived exosomes (TDEs) participate in most hallmarks of ESCC, including tumorigenesis, invasion, angiogenesis, immunologic escape, metastasis, radioresistance, and chemoresistance. Published reports have delineated that exosomeencapsulated cargos like miRNAs may have utility in the diagnosis, as prognostic biomarkers, and in the treatment of ESCC. This review summarizes the function of exosomes in the neoplasia, progression, and metastasis of ESCC, which improves our understanding of the etiology and pathogenesis of ESCC, and presents a promising target for early diagnostics in ESCC. However, recent studies of exosomes in the treatment of ESCC are sparse. Thus, we introduce the advances in exosome-based methods and indicate the possible applications for ESCC therapy in the future.

Keywords: esophageal squamous cell carcinoma, exosome, exosomal RNAs, biomarker, diagnosis

\section{INTRODUCTION}

Esophageal cancer ranks the seventh most prevalent malignancy and the sixth-highest cancerrelated mortality globally (1). Esophageal cancer is broadly divided into esophageal squamous cell carcinoma (ESCC) and esophageal adenocarcinoma (2). The incidence of esophageal cancer in men is approximately three to four times that in women and varies among countries (3). The highest rates of ESCC are found in Eastern Asia, where ESCC accounts for more than 90\% of esophageal cancers (4). Despite significant progress in diagnosis and treatment, ESCC is often identified late, which leads to delayed treatment. The reason for this challenge can be attributable to multiple aspects: in the early stage, ESCC is characterized by a lack of specific symptoms and definitive 
diagnosis; coming to the advanced stage, ESCC can exhibit considerable metastatic potential and strong resistance to conventional treatment. Given the above, ESCC is commonly presented with a poor prognosis, as the 5-year survival rate of late-stage ESCC is approximately $10-20 \%$ (5). Hence, more effort is urgently needed to reveal the mechanisms of tumorigenesis and increase the early diagnosis rate of ESCC.

In the last decade, there has been a steep increase in the investigations focusing on extracellular vesicles' (EVs') physiological and pathological functions, referring to multiple subtypes of cell-released, membranous structures (6-8). In particular, exosome is among the most studied and deliberated population of EVs in the rapidly growing number of publications. Notably, MISEV2018 guidelines have endorsed that the term "exosome" should be applied strictly to an EV of endosomal origin owing to the difficulties to confirm such an origin after an EV has left the cell $(8,9)$. According to the conventional description of exosome (from about 30 to $200 \mathrm{~nm}$ in diameter) (10), it would be more appropriate to nominate "exosome" as "small extracellular vesicle (sEV)", as the guidelines propose. However, considering the number of studies published before the criteria were issued, we decide to preserve "exosome", referring to "small extracellular vesicle of endosomal origin", in this review to help readers adapt to the new standard.

With molecular heterogeneity, exosomes encapsulate diverse bioactive molecules, ranging from nucleic acid (including DNA and RNA) to proteins, lipids, and other metabolites (11). Exosomes have mediated a new paradigm of intercellular communication via the transfer of bioactive molecules from donor cells to recipient cells, and they function in both normal physiology and acquired pathological activities, such as reproduction, immune responses, metabolic and cardiovascular diseases, ischemic diseases, neurodegeneration, and malignant tumors (12-17). In the process of tumorigenesis, exosomes can participate in the formation of the tumor microenvironment (TME), the proliferation of cancer cells, angiogenesis, metastasis, therapy resistance, and many other physiological and pathological processes (18). The amounts and cargos of exosomes derived from the same cell can dramatically vary from different conditions, and the heterogeneity of exosomal cargos has been recognized among different individuals (19-21). Considering the homogeneity between exosomes and donor cells, these cargos of the tumor-derived exosomes (TDEs) carry cancerrelated information and allow them to fulfill diagnostic functions, serving as tumor biomarkers of ESCC that can be detected in earlystage cancer $(22,23)$. Moreover, the specialty of exosomes in delivering diverse and specific functional cargos into recipient cells has accelerated their clinical application in the therapy of patients with malignant tumors or other diseases (24-26). Ongoing studies and trials have proven that exosomes can be engineered to carry specific lipids, proteins, and other chemotherapeutic agents to targeted cells or organs and facilitate the treatment of several diseases (27-30).

The primary objectives of this review are to introduce the biology of exosomes, summarize the function of exosome-carried cargos in the initiation and development of ESCC, and discuss the potential clinical applications in both the early diagnosis and treatment of ESCC (Figure 1).

\section{BIOLOGY OF EXOSOME (sEVs)}

Exosomes, which should have been called sEVs following MISEV2018 guidelines, are a kind of lipid bilayer-encapsulated, nanosized vesicles that are enriched in specific DNA, RNA, lipids, proteins, and bioactive compounds (10).

Generally, the biogenesis and releasing of exosomes involve the double invagination of the plasma membrane and the sequential generation of multivesicular bodies (MVBs) and

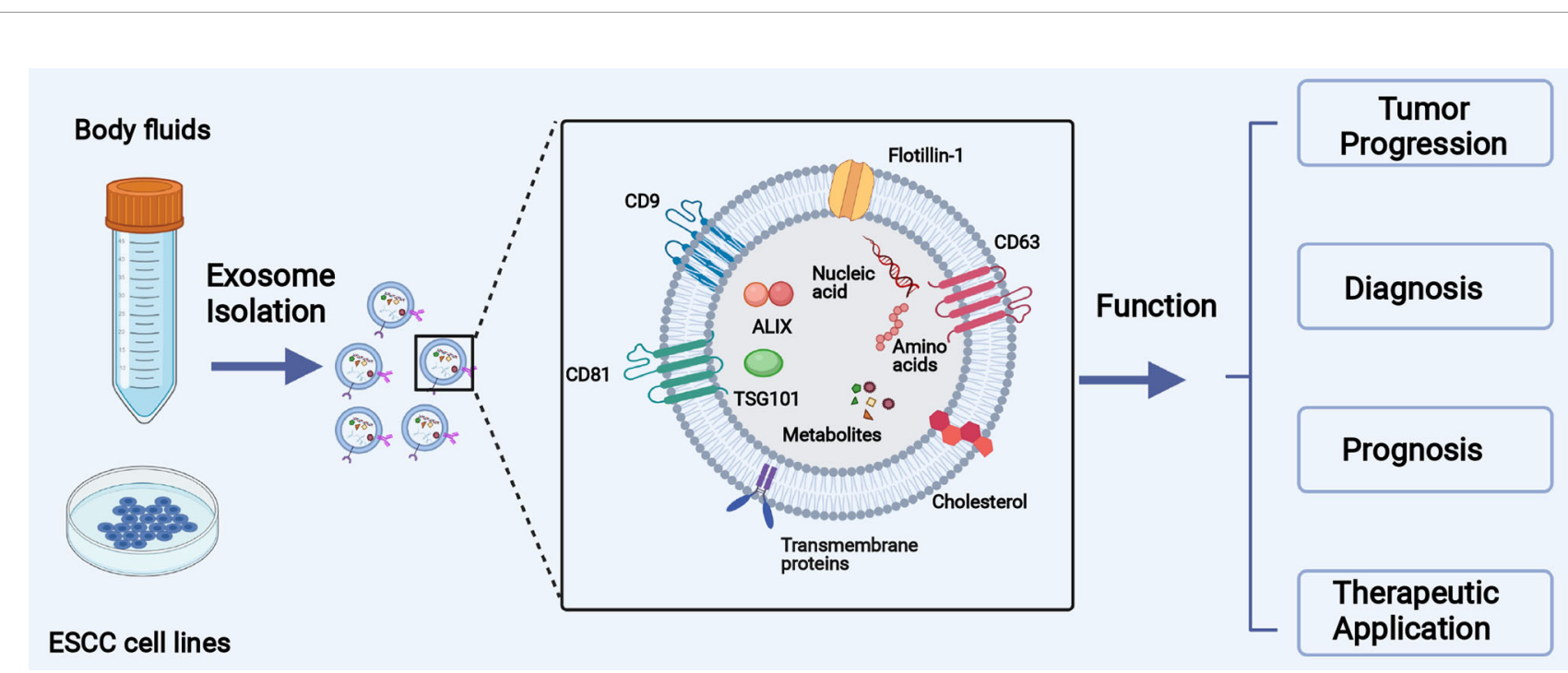

FIGURE 1 | The main objective of this review is to introduce the biology of exosomes, summarize the function of exosomal cargos in the initiation and development of ESCC, and collect the clinical application of exosomes in the diagnosis and treatment of ESCC. 
intraluminal vesicles (ILVs) (11) (Figure 2). The first invagination of the plasma membrane forms a cup-shaped structure, containing cell-surface proteins and soluble proteins from the extracellular milieu. Then, the cup-shaped plasma membrane buds in the inner side of the cell, which gives rise to an early-sorting endosome (ESE) and, sometimes, may directly fuse with a preexisting ESE. Meanwhile, the endoplasmic reticulum (ER), mitochondria, and trans-Golgi network (TGN) also engage with the formation of the ESEs. Furthermore, the ESEs can also blend into the ER and TGN, possibly interpreting how the extracellular and cell-surface ingredients enter them (31-36). Afterward, ESEs form latesorting endosomes (LSEs) and subsequently give rise to MVBs (also named as multivesicular endosomes). MVBs come into being with the inward invagination of the endosomal limiting membrane, the double invagination of the plasma membrane exactly, and they will be released as intraluminal vesicles (ILVs) after fusion with the plasma membrane. During the process, cytoplasmic constituents can enter the newly forming ILVs, leading to further changes in the future exosomal cargos (32, 37). Some proteins, including endosomal sorting complexes required for transport proteins (ESCRT), soluble $\mathrm{N}$ ethylmaleimide-sensitive factor attachment protein receptors (SNAREs), apoptosis-linked gene 2 -interacting protein $\mathrm{X}$ (ALIX), tumor susceptibility gene 101 (TSG101), Rab GTPases, CD9, CD63, and CD8 1, play a critical part in the origin and biogenesis of exosomes, and some are regarded as markers of exosomes $(38,39)$. After being secreted into the extracellular milieu, exosomes are delivered and identified by the targeted recipient cells. As a result, they alter the phenotype and biological response of these recipient cells (40). The mechanism of exosome uptake is complex; the fate of the exosomal contents and the molecular alterations induced in recipient cells add complexity to the cell-cell crosstalk (41). When docking the recipient cell, exosomes can activate signaling pathways by straightly interacting with the receptors on the cell surface, directly fusing with the plasma membrane, or getting internalized (42). Firstly, the interaction between exosomes and extracellular

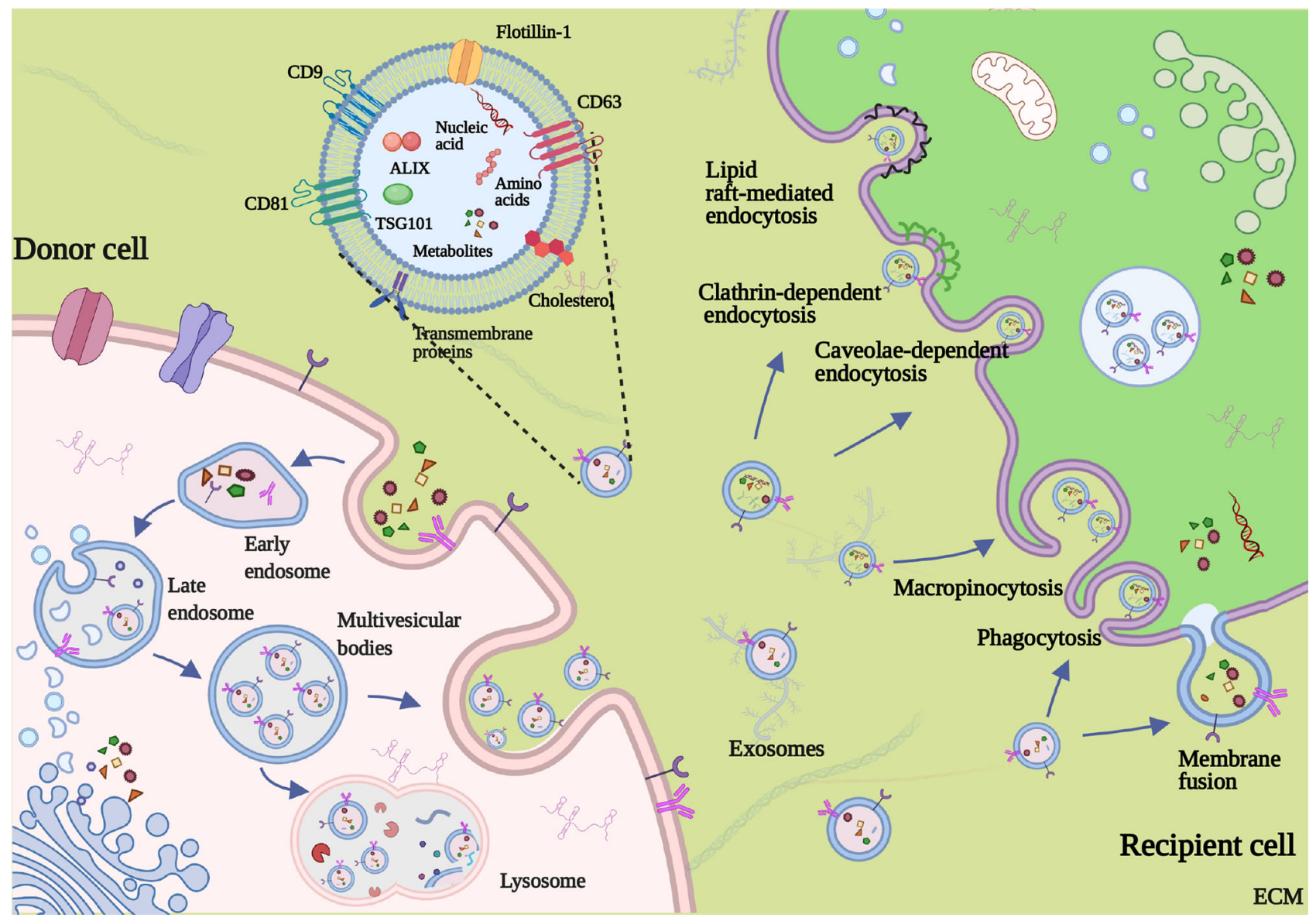

FIGURE 2 | Formation, secretion, and uptake of exosome. Invagination of the plasma membrane forms the early endosome. Then, inward invagination of endosomes gives birth to the formation of multivesicular bodies (MVBs) containing intraluminal vesicles (ILVs). Exosomes are eventually released by fusing of MVBs to the plasma membrane and the exocytosis of ILVs. The mechanism of exosome uptake includes direct fusing with the plasma membrane, macropinocytosis, phagocytosis, caveolin-mediated, lipid raft-mediated endocytosis, and clathrin-dependent endocytosis. 
receptors has been reported to exist in mediating immunomodulatory. For example, Tkach et al. showed that exosomes secreted by dendritic cells (DCs) could carry MHCpeptide complexes and bind Toll-like receptor ligands on the bacterial surface, which induced the activation of bystander DCs and T lymphocytes $(43,44)$. Besides, the families of SNAREs and Rab proteins were reported to mediate the fusion with the plasma membrane and release exosomal cargos (45). Moreover, as representative of internalization, the mode of clathrinmediated endocytosis has been demonstrated in multiple cell types, such as gastric epithelial cells, colon tumor cells, and cardiomyocytes (46-48). Different exosomal uptake modes may be attributed to the properties of the exosome that shuttles cargos and the metabolic status of recipient cells, but the precise regulating mechanism deserves additional in-depth exploration.

\section{ROLES OF EXOSOME IN THE INITIATION AND DEVELOPMENT OF ESCC}

Exosome-related research has focused on the exosome's ability to efficiently transfer an array of selected cargos to recipient cells (49).
Studies about the function of exosomes in malignant tumors have developed substantially compared with studies in other fields, and increasing evidence supports exosome-mediated intercellular crosstalk in the TME $(50,51)$. Accumulating evidence has revealed that exosomes are involved in many features of malignant tumors, including neoplasia, progression, metastasis, angiogenesis, and drug resistance (52-55). In recent years, research involving the correlation between exosomes and ESCC has increased rapidly and yielded valuable information about the function of exosomes in ESCC progression. Here, we summarize the biological function of exosomes that shuttle cargos in the initiation and development of ESCC (Figure 3), as shown in Table 1. Understanding the function of exosomes and how to use exosomes in ESCC cells to transfer nanoparticles in cell-cell communication are topics at the forefront of oncobiology and may open new avenues for ESCC treatment.

\section{Tumor Microenvironment (TME)}

The occurrence of ESCC is a result of a continuous accumulation of mutations in esophageal cells and oncogenic alteration in the TME (75). The TME involves blood vessels, the extracellular matrix (ECM), cytokines, and stromal cells and is indispensable

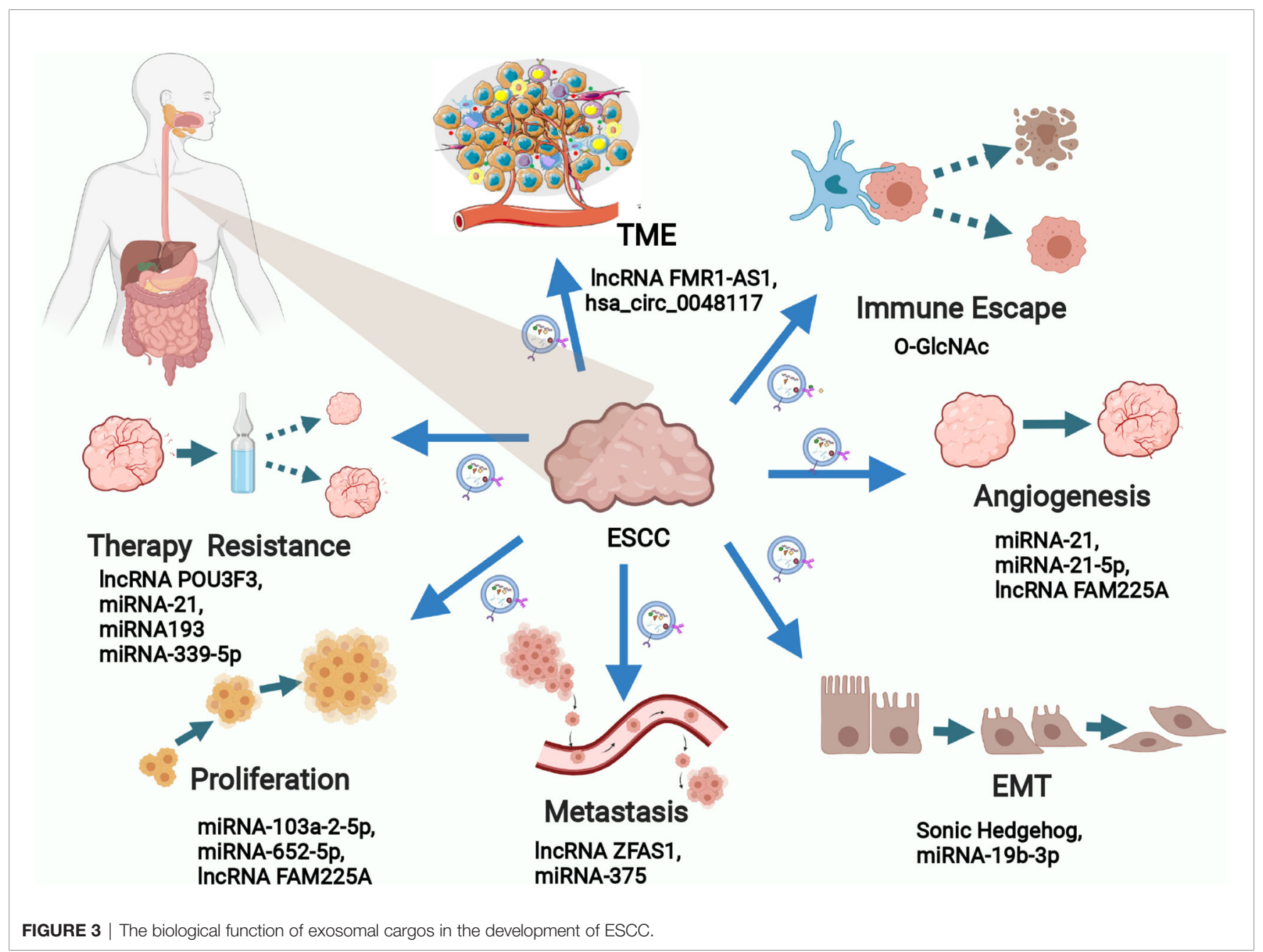


TABLE 1 | Roles of exosome in the initiation and development of ESCC.

\begin{tabular}{|c|c|c|c|c|}
\hline Type & Molecule & Function & Signaling/Target & Ref. \\
\hline \multirow[t]{9}{*}{ miRNA } & miRNA-19b-3p & Reduce apoptosis rate, and promote migration and invasion & PTEN & $(56)$ \\
\hline & miRNA-103a-2-5p & Promote proliferation and migration & $\mathrm{CDH} 11$ gene and $\mathrm{NR} 3 \mathrm{C} 1$ gene & $(57)$ \\
\hline & miRNA-652-5p & Inhibit proliferation and metastasis & PARG and VEGF pathways & (58) \\
\hline & miRNA-21-5p & Promote angiogenesis & PDCD4 and PTEN/Akt pathway & (59) \\
\hline & miRNA-21 & Promote angiogenesis & SPRY1 & (60) \\
\hline & & Promote chemotherapy resistance & PDCD4 & $(61)$ \\
\hline & miRNA-375 & Promote apoptosis, and inhibit proliferation, invasion, migration & ENAH & $(62)$ \\
\hline & miRNA-193 & Promote chemotherapy resistance & VEGF and Jak-STAT pathways & (63) \\
\hline & miRNA-339-5p & Enhance radiosensitivity & Cdc25A & (64) \\
\hline \multirow[t]{6}{*}{ IncRNA } & FMR1-AS1 & Maintain TME, promote proliferation, invasion, and inhibit apoptosis & TLR7/NFкB/c-Myc pathway & (65) \\
\hline & ZFAS1 & Promote proliferation, migration, invasion, and inhibit apoptosis & miRNA-124/STAT3 axis & (66) \\
\hline & FAM225A & Promote apoptosis, and inhibit proliferation, migration, and invasion & miRNA-206/NETO2/FOXP1 & (67) \\
\hline & UCA1 & Inhibit proliferation, invasion and migration & miRNA-613 & (68) \\
\hline & PART1 & Promote chemotherapy resistance & miRNA-129/Bcl-2 pathway & (69) \\
\hline & POU3F3 & Promote proliferation and chemotherapy resistance & $\mathrm{IL}-6$ & $(70)$ \\
\hline circRNA & has_circ_0048117 & Promote invasion and migration & miRNA-140/M2 macrophage & (71) \\
\hline \multirow[t]{3}{*}{ Others } & Sonic Hedgehog & Promote proliferation and migration & Hedgehog pathway & $(72)$ \\
\hline & O-GlcNAc transferase & Promote the immune escape & PD-1 & (73) \\
\hline & HMGB1 & Promote the immune escape & PD-1 positive TAMs & (74) \\
\hline
\end{tabular}

in tumorigenesis because it provides necessary conditions for tumor growth and manipulates the interaction between cancer cells and their surroundings (76). Exosomes act as an essential role in the formation and reprogramming of the TME, as has been widely documented in many cancer types (77-79). In ESCC, Li et al. found that exosomal FMR1 antisense RNA 1 (FMR1-AS1) could remodel the TME in ESCC (65). The study confirmed that the FMR1-AS1 exosomes were secreted from cancer stem-like cells (CSCs) of ESCC, which transferred stemness phenotypes to recipient non-CSCs in the TME through the mechanism of activating toll-like receptor 7nuclear factor $\kappa \mathrm{B}$ (TLR7-NFאB) signaling, upregulating the $\mathrm{c}$ Myc level in recipient cells. Another example of exosomal cargos promoting the TME formation involves circ-0048117-rich exosomes derived from hypoxic ESCC cells, promoting M2 macrophage polarization to alter the components in the microenvironment (71). Researchers indicated that hypoxic exosomes modulated the TME in ESCC via the transformation of endothelial cell phenotypes and transcriptomes, which enhance angiogenesis and metastasis. Moreover, the exchange of exosomes in cancer cells and the stroma is bidirectional, and cancer-associated fibroblasts (CAFs) can also secrete exosomal Sonic Hedgehog to promote the generation of TME in ESCC (72). These findings suggest that exosomes can play an essential role in the formation, remolding, and normal function of the TME and that novel therapies targeting the TME may be a new approach to cancer treatment.

\section{Proliferation and Apoptosis}

The progression of ESCC results from rapid growth and expansion of cancer cells, which may incur tumor survival and defiance to therapy. Exosomes can influence the growth of ESCC by mediating the apoptosis, cycle, and proliferation rate of ESCC cells (80). Molecular profiling has indicated that exosomal miRNA-19b-3p from EC9706 cells targets PTEN, a well-known tumor suppressor gene, to regulate the apoptosis of ESCC (56).
A similar study elucidated that exosomal lncRNA ZNFX1 antisense RNA 1 (ZFAS1) derived from EC109 cells regulates ESCC proliferation, apoptosis, and migration via targeting the miRNA-124/STAT3 signaling pathway (66). Cancer cell-derived exosomes can regulate the ratio of G1-phase cells and influence the cycle and migration ability of ESCC cells (81). Some researchers have demonstrated that the proliferation and apoptosis of ESCC cells are modulated by several other exosomal cargos, including miRNA-103a-2-5p, miRNA-652$5 \mathrm{p}$, IncRNA Family with sequence similarity 225 member A (FAM225A), and lncRNA urothelial cancer-associated 1 (UCA1) $(57,58,67,68)$. Generally, these exosomal contents can work by mediating the expression of proliferation- or apoptosis-related proteins and triggering a subsequent signaling pathway. Importantly, these studies also indicated that the identified exosomal RNAs and other exosomal contents can facilitate the proliferation ability of tumor cells alone and may concurrently alter the potential for migration, angiogenesis, and metastasis. Above all, the activation of cell proliferation cannot entirely be attributed to the expansion and development of ESCC; instead, it results from several steps, including migration and metastasis, angiogenesis, immune response, and therapy resistance. The role of exosomes in these steps of tumor development is explored in the following sections.

\section{Angiogenesis}

Angiogenesis, a critical phase during neoplasia, migration, and metastasis, is a multistep formation of neovascularization through which cancer cells obtain sufficient oxygen, nutrition, and energy (82). Reports have illustrated that some exosomes could play a role in inducing angiogenesis in many cancer types (83). Exosomes can deliver numerous pro-angiogenic bioactive substances, including vascular endothelial growth factor (VEGF), miRNAs, or other bioactive mediators. Published data suggest that exosomal cargos accelerate angiogenesis by suppressing the expression of anti-angiogenesis genes and promoting the 
expression of pro-angiogenic genes $(84,85)$. For example, compared with normal exosomes, hypoxic exosomes have played a unique role in facilitating the aggressive behavior of human umbilical vein endothelial cells (HUVECs) both in vitro and in vivo, and HUVECs exposed to hypoxic exosomes induce enhanced proliferation, metastatic dissemination, and vessel formation ability in ESCC (86). Consistent with that study, Zhuang showed that ESCC cell-derived exosomal miRNA-21 potentiates the angiogenesis ability of HUVEC by targeting sprouty RTK signaling antagonist 1 (SPRY1) in ESCC (60). Moreover, exosomal miRNA-21-5p has been shown to significantly promote the angiogenesis of targeted cells via the activation of programmed cell death 4 and downgrading of the signaling pathway or the PTEN/Akt signal pathway in ESCC (59). Similar findings have suggested that exosomal lncRNA FAM225A accelerates ESCC angiogenesis by binding to miRNA206 and promoting NETO2 and FOXP1 expression (67). Given the pivotal role of angiogenesis in ESCC development and progression, exosome-related research may provide a new avenue to counteract these mechanisms of progression in ESCC, and these discoveries will become even more promising if they are linked to antitumor vascular drugs.

\section{Epithelial-Mesenchymal Transition and Metastasis}

Metastasis is a critical step in tumor growth, and it remains a paramount threshold for cancer treatment and the chief cause of cancer mortality (87). Metastasis is a complicated and intricate process involving several steps such as epithelial-mesenchymal transition (EMT) of cancer cells, migration and infiltration into surrounding tissues, intravascular transport, and recognition and establishment in distant tissues $(88,89)$. Intercellular communication by delivering exosomes from primary tumor cells to the local microenvironment or distant organs is crucial for the phenotypic change and biological aggressive behavior of cancer cells, forming a pre-metastatic niche, and attachment and implantation to distant organs (90). Esophageal cancer cellderived exosomes can modulate gene expression of recipient cancer cells, leading to an increased risk of invasion and metastasis. For example, the Sonic Hedgehog ( $\mathrm{SHH}$ ) signaling pathway, which has played important roles during development and in cancer $(91,92)$, can drive tumorigenesis and progression of ESCC. One study showed that exosomal Sonic Hedgehog derived from cancer-associated fibroblasts (CAFs) could increase the activation of N-cadherin and Vimentin in EC109 cell lines and consequently promoted the growth and migration abilities of ESCC (72). Similarly, exosomes derived by infiltrating T cells from irradiated esophageal carcinoma can incur the EMT in ESCC and facilitate metastasis (93). Conversely, human umbilical cord mesenchymal stem cells can suppress enabled homolog (ENAH) expression and decrease the invasion and migration ability of ESCC via the exosomal delivery of miRNA375 (62). Exosomes play a pivotal role in forming a premetastatic niche in distant organs in ESCC, like in gastric cancer and breast cancer (94). This role may be attributed partly to the predisposition of early lymphatic metastasis in ESCC; metastatic dissemination in the liver or lung is relatively rare (95). In conclusion, exosomal cargos can exert pro-tumorigenic effects in most steps of ESCC metastasis, thus promoting the metastatic potential of ESCC. The studies discussed here may offer new insights that help the researcher understand the function of exosomes in metastatic ESCC and uncover exosome-based therapies that may curb cancer metastasis.

\section{Immune Response and Therapy Resistance}

The elimination of tumor cells relies heavily on the immune system in vivo and exogenous therapies, such as drugs or irradiation (96). The immune system is an intricate network that can guard the body by monitoring, recognizing, and eliminating foreign invaders, such as bacteria, parasites, and endogenous antigens like cancer cells (97). These days, when we talk about the relationship between immune response and tumors, programmed cell death protein 1 (PD-1) is one of the monumental works that are closely associated with it indeed (98). A recent study suggested that $\mathrm{O}$-linked $\beta-\mathrm{N}$ acetylglucosamine (O-GlcNAc) transferase from stem cells of ESCC can upregulate PD-1 in CD8+ T cells and promote cancer immunosuppression (73). Furthermore, exosomes isolated from serum, plasma, urine, or other body fluids of patients with ESCC, as well as from ESCC cell lines, can reduce B-cell proliferation and induce an increase in interleukin-10 positive regulatory $\mathrm{B}$ cells and a high level of PD-1 regulatory B cells (99). Besides, another research demonstrated that exosomal High Mobility Group Box 1 (HMGB1) obtained from ESCC could successfully trigger clonal expansion of PD1 positive tumorassociated macrophages (TAMs), which thereby created conditions for the development of ESCC (74). These findings above contribute to understanding exosomal functions in the immune response and illustrate exosomes' therapeutic application that promotes antitumor immune responses.

Currently, chemotherapy is regarded as the most effective therapy for ESCC after surgery, and tumor recurrence can be attributed mainly to chemotherapy resistance $(100,101)$. Tumors can achieve drug resistance in many ways, including via information exchange by exosomes (102). A recent study indicated that exosomes carrying lncRNA prostate androgenregulated transcript 1 (PART1) derived from Gefitinib-resistant cells confer cisplatin resistance in ESCC (69). Furthermore, several studies have elucidated that many other exosomeshuttled cargos, such as lncRNA POU class 3 homeobox 3 (POU3F3), miRNA-21, and miRNA-193, are involved in Cisplatin resistance in $\operatorname{ESCC}(61,63,70)$. Apart from roles in chemoresistance, exosomes reportedly regulate radiation therapy and induce radiation-induced bystander effect (RIBE) (103). Exosomal miRNA-339-5p can mediate the radiosensitivity of ESCC by downregulating cell division cycle 25A (Cdc25A) and can predict outcomes in preoperative radiotherapy (64). These discoveries capture the role of exosomes in therapy resistance and shed light on how engineered exosomes may deliver therapeutic agents for ESCC treatment in the future. 


\section{CLINICAL APPLICATION OF EXOSOME IN ESCC}

\section{Diagnostic Potential of Exosomal Cargos as Biomarkers for ESCC}

ESCC is considered silent cancer because it lacks characteristic manifestations in the early stage. Patients are frequently diagnosed in middle or late stages, delaying the optimal time for treatment and causing a high mortality rate (104). Therefore, it is paramount to find early diagnostic methods to identify patients with ESCC to benefit from early interventions (105). Currently, the gold standard for the diagnosis of ESCC is tissue biopsy under endoscopy, an invasive inspection with correspondingly high costs (106). A non-invasive diagnostic method in early-stage ESCC is urgently needed. Researchers have made great efforts to screen for ESCC biomarkers; possible candidates include circulating tumor cells (CTCs), serum miRNAs, small extracellular vesicles (sEVs), as well as circulating tumor DNA (ctDNA) $(107,108)$. Exosomal cargos serve as promising tumor biomarkers because they reflect the donor cell and their presence in various biological fluids (109111). New research into the potential application of exosomes as tumor biomarkers has emerged and yielded valuable information for additional in-depth exploration $(112,113)$. Growing evidence has confirmed that exosomal RNAs outperform peripheral blood-free RNAs in cancer diagnosis because of several advantages: First, exosomes exist in all biological fluids and are easily accessible compared with plasma. Second, exosomal cargos can be well protected from degradation by enzymes or elimination by the biological barrier. Third, the components of exosomes have high homology with donor cells, which may encourage a higher specificity of exosome-based detection. Last, the concentration of exosomal cargos is higher than the expression of plasma RNAs (114-116). Here, we focus on state-of-the-art exosomal cargos in ESCC.

The distinct expression of exosome-shuttling contents between cancer cells and normal cells supports the application of exosomes as biomarkers for ESCC. Among these exosomal compounds, exosome-carrying miRNAs are most investigated. For example, Zeng corroborated that exosome-shuttled miRNA$19 b-3 p$ separated from patients with ESCC is significantly upregulated compared with healthy controls, suggesting that serum exosome-encapsulated miRNA-19b-3p highlights the potential utility of exosomal RNAs in the early detection of ESCC (56). A study from 51 patients with ESCC and 41 with benign diseases showed that plasma exosomal miRNA-21 levels were significantly elevated in ESCC versus benign diseases so that they were suitable to be biomarkers for early diagnosis of ESCC (117). Except for the effect of exosomes on the differential diagnosis of ESCC, lymph node metastasis and TNM grade have been associated with the expression of some exosomal cargos that may serve as independent prognostic factors of ESCC. Lu et al. suggested that tumor cells-derived exosomes markedly upregulated the expression of hsa-circ-0048117 under the condition of hypoxia-a change that may be positively correlated with advanced $\mathrm{T}$ and $\mathrm{N}$ stages serves as a biomarker for progression (71). Similar studies have revealed that downregulated exosomal miRNA-339-5p and miRNA-652-5p in the serum are related to advanced TNM stages and a higher lymph node metastasis rate $(58,64)$. Moreover, several studies have indicated that higher serum exosomal miRNA-182, miRNA-766-3p, lncRNA POU3F3, and has-circ-0026611 levels in patients with ESCC are positively related to poor prognosis (70, 118-120). Except for exosomal RNAs, a small amount of exosome-carrying protein has been reported previously. The over-expression of Stathmin-1, regarded as microtubule depolymerization protein, is related to the process of tumor spread, adverse clinical outcomes, and chemoresistance in many types of cancer, especially squamous cell carcinoma, by controlling cell division, proliferation, and migration (121124). In ESCC, Yan et al. corroborated that the average expression of stathmin-1 elevated in oncogenic exosomes, and the serum stathmin-1 level in patients with ESCC was obviously higher than that of healthy individuals (125). In addition, elevated concentration of stathmin-1 was related to lymphatic metastasis and late staged cancer.

Thus, several exosomal cargos have been identified as biomarkers for ESCC in applying possible diagnosis and potential prognosis, as described in Table 2. It is noteworthy that few literature reports address the diagnostic value of these molecules; the diagnostic efficacy of most candidates, apart from few miRNAs like miRNA-21, deserve additional validation. Much work remains before exosomal cargos can be applied as ideal biomarkers of ESCC. In addition, readers should note that some of the articles we referenced were published before the MISEV2018 guidelines were issued, which means the research methods they applied might not meet the standard of the guidelines. For example, few works failed to further validate sEV-specific markers, which is not recognized by the standards of EV isolation protocols in MISEV2018. Therefore, we hope readers accommodate the term "small extracellular vesicle" to replace "exosome",

\section{Potential Application of Exosomes in Treatment of ESCC}

In addition to having a diagnostic role in cancer, exosomes have potential use in disease therapy. The characteristic property in transferring selected payloads to recipient cells has translated into potential applications for treating many diseases, including cancer and cardiovascular diseases (134-136). However, recent articles published on the potential application of exosomes in the treatment of ESCC are sparse. Thus, this section mainly summarizes exosome-based therapy in other cancers and introduces the exosomes that may be potential targets for ESCC therapy in the future. Researchers harness engineered exosomes to deliver chemotherapeutic agents, achieving better performance than traditional vectors like liposomes (49). Theoretically, exosomes have the following advantages: First, the membrane structure of an exosome can protect pharmacological agents from degradation. Second, exosomes naturally exist in all biological fluids, and thus they can be well tolerated when introduced into the body. They can efficiently 
TABLE 2 | Exosomal cargos as biomarkers for ESCC.

\begin{tabular}{|c|c|c|c|c|}
\hline Type & Molecules & Origin & Potential Functions & Ref. \\
\hline \multirow[t]{9}{*}{ miRNA } & miRNA -19b-3p & Serum & Distinguish ESCC patients from healthy individuals & $(56)$ \\
\hline & miRNA -21 & Serum & Predict TNM stage & $(117)$ \\
\hline & miRNA $-652-5 p$ & Serum & Predict TNM stage, lymph node metastasis, and survival rate & $(58)$ \\
\hline & miRNA -339-5p & Serum & Predict radiotherapy sensitivity and survival rate & (64) \\
\hline & miRNA -182 & Serum & Distinguish ESCC patients from healthy individuals, predict TNM stage and survival rate & (118) \\
\hline & miRNA -766-3p & Serum & Predict TNM stage and survival rate & (119) \\
\hline & miRNA -103a-2-5p & Serum & Predict survival rate & $(57)$ \\
\hline & miRNA -93-5p & Serum & Predict survival rate & (126) \\
\hline & $\begin{array}{l}\text { chr 8-23234-3p, } \\
\text { chr 1-17695-5p, } \\
\text { chr 8-2743-5p, } \\
\text { miRNA-432-5p }\end{array}$ & Serum & Predict lymph node metastasis & $(127)$ \\
\hline \multirow[t]{10}{*}{ IncRNA } & POU3F3 & Serum & Predict chemotherapy sensitivity and survival rate & $(70)$ \\
\hline & RP5-1092A11.2 & Serum & Distinguish ESCC patients from esophagitis patients and from healthy individuals & (128) \\
\hline & NR_039819 & Serum & Distinguish ESCC patients from healthy individuals & (129) \\
\hline & NR_036133 & & & \\
\hline & NR_003353 & & & \\
\hline & ENST00000442416.1 & & & \\
\hline & ENST00000416100.1 & & & \\
\hline & UCA1 & Serum & Early diagnosis & (68) \\
\hline & FMR1-AS1 & Serum & Predict survival rate, especially in female ESCC patients & $(65)$ \\
\hline & POU3F3 & Serum & Predict survival rate & (130) \\
\hline \multirow[t]{3}{*}{ circRNA } & hsa-circ-0048117 & Serum & Predict TNM stage & $(71)$ \\
\hline & hsa_circ_0026611 & Serum & Predicted lymph node metastasis and survival rate & (120) \\
\hline & $\begin{array}{l}\text { hsa_circ_0001946 } \\
\text { hsa_circ_0001946 }\end{array}$ & Serum & Predict recurrence and survival rate & $(131)$ \\
\hline \multirow{3}{*}{$\begin{array}{l}\text { Other } \\
\text { biomarkers }\end{array}$} & G-NchiRNA & Salivary & Reflect tumor burden, evaluate therapeutic response and predict survival rate & $(132)$ \\
\hline & uc.189 & Serum & Evaluate lymph node metastasis & (133) \\
\hline & Stathmin-1 & Serum & $\begin{array}{l}\text { Differentiate patients with ESCC from healthy individuals, and be associated with lymph node metastasis and } \\
\text { advanced cancer stage }\end{array}$ & $(125)$ \\
\hline
\end{tabular}

penetrate biological barriers and deliver targeted cargo with minimal immune clearance. Third, some exosomes have receptor-targeting features resulting from the heterogeneity of exosomal surface proteins, enabling targeted delivery of therapeutic agents for cancer. Last, because they are shed by all cells as part of their normal physiology, exosomes may induce less toxicity and minimize other adverse reactions even with repeated injection (137-140). Therefore, exosomes may have a bright future as nanocarriers for cancer treatment.

Currently, researchers are committed to designing exosomes to encapsulate therapeutic agents and conducting studies that yield valuable information about the application of exosomes for the administration of diseases. For example, gene-engineered exosome-thermosensitive liposomes can block the CD47 immune checkpoint and improve the macrophage-mediated elimination of cancer cells (30). Pan et al. indicated that urinary exosome-based engineered nanovectors could help deliver targeted homologous treatment in prostate cancer and may exemplify a novel, efficient, and facile therapy strategy (29). So far, evidence about the function of engineered exosomes in cancer therapy is primarily from cancers like gastric cancer or prostate cancer, not from ESCC; relevant data in ESCC are, at best, sparse. However, despite the many unanswered questions about their clinical application, exosomes show great potential to facilitate ESCC therapy. In addition, accumulating research has suggested that engineered exosomes in vitro can play a paramount role in different experimental settings, but more exploration is needed before these findings translate into clinical practice (141). Also, research must guarantee the homogeneity of exosomes by standardizing protocols for exosome isolation, preparation, and route of administration (8). Currently, inefficient isolation methods of exosomes cannot provide sufficient exosomes to meet cancer therapy requirements (142). Identifying ways to prevent exosomes from being taken up by other cells and to drive the engineered vehicles to targeted cells or organs remains a considerable challenge (143-145). Overall, engineered exosomes provide a promising therapeutic option for cancer treatment, although the utility of this strategy in clinical practice requires additional exploration.

\section{CONCLUSIONS AND PERSPECTIVES}

As referred to above, substantial evidence has delineated that exosomes and their inclusion, such as DNA, RNA, proteins, lipids, and other biological complexes, significantly affect cellular pathways and mediate pathophysiology behaviors, involving cell growth oncogenesis and tumor differentiation. EVs may act as biomarkers for early ESCC diagnosis, therapeutic monitoring, or prognosis evaluation. The association with exosomal cargos and disease state could be used in diagnostic and prognostic biomarkers for early ESCC, such as miRNA-21 was recognized 
as an exosome-derived small RNA superior to traditional tumor markers for early diagnosis of ESCC (117). It should be noted that a panel of miRNAs has delineated a higher sensitivity and specificity compared with a single miRNA, but researchers have to make a considerable effort to screen for miRNA panels that can be used in early diagnosis for ESCC $(129,130)$. In addition, there are some limitations in the clinical application of circulating exosome-related analysis. The separation and purification technology is mainly used in scientific research but rarely applied in clinical practice. Exosome-testing kits are developing, and some laboratory investigations and clinical studies on ESCC exosomes are ongoing or are forthcoming. For example, a newly developed commercial kit (ExoLutE ${ }^{\circledR}$ ) utilizing the principle of size-exclusion spun column improves the efficiency and purity of circulating exosome separation compared to conventional kits (146).

Exosomes have been widely regarded as a promising carrier of anticancer drugs, which were proved in animal studies. If engineering exosomes that carried anticancer agents could be realized, the delivery of therapeutic agents by exosomes would make exosomes ideal vectors for cancer therapy (147). To date, evidence on the function of engineered exosomes in cancer therapy has mainly come from other cancers, such as pancreatic or prostate cancer $(29,148)$, and data on ESCC have been sparse at best. With the development of science and technology, large-scale clinical studies or trials on ESCC exosomes will undoubtedly be carried out. It is believed that

\section{REFERENCES}

1. Sung H, Ferlay J, Siegel RL, Laversanne M, Soerjomataram I, Jemal A, et al. Global Cancer Statistics 2020: GLOBOCAN Estimates of Incidence and Mortality Worldwide for 36 Cancers in 185 Countries. CA Cancer J Clin (2021) 71(3):209-49. doi: 10.3322/caac.21660

2. Thrift AP. Global Burden and Epidemiology of Barrett Oesophagus and Oesophageal Cancer. Nat Rev Gastroenterol Hepatol (2021) 18(6):432-43. doi: 10.1038/s41575-021-00419-3

3. Yang S, Lin S, Li N, Deng Y, Wang M, Xiang D, et al. Burden, Trends, and Risk Factors of Esophageal Cancer in China From 1990 to 2017: An Up-toDate Overview and Comparison With Those in Japan and South Korea. J Hematol Oncol (2020) 13(1):146. doi: 10.1186/s13045-020-00981-4

4. Pakzad R, Mohammadian-Hafshejani A, Khosravi B, Soltani S, Pakzad I, Mohammadian M, et al. The Incidence and Mortality of Esophageal Cancer and Their Relationship to Development in Asia. Ann Transl Med (2016) 4 (2):29. doi: 10.3978/j.issn.2305-5839.2016.01.11

5. Qin Q, Ge X, Wang X, Wang L, Li C, Chen J, et al. Stage III Esophageal Squamous Cell Carcinoma Patients With Three-Dimensional Conformal or Intensity-Modulated Radiotherapy: A Multicenter Retrospective Study. Front Oncol (2020) 10:580450. doi: 10.3389/fonc.2020.580450

6. Stein JM, Luzio JP. Ectocytosis Caused by Sublytic Autologous Complement Attack on Human Neutrophils. The Sorting of Endogenous PlasmaMembrane Proteins and Lipids Into Shed Vesicles. Biochem J (1991) 274 (Pt 2):381-6. doi: 10.1042/bj2740381

7. Witwer KW, Soekmadji C, Hill AF, Wauben MH, Buzas EI, Di Vizio D, et al. Updating the MISEV Minimal Requirements for Extracellular Vesicle Studies: Building Bridges to Reproducibility. J Extracell Vesicles (2017) 6 (1):1396823. doi: 10.1080/20013078.2017.1396823

8. Thery C, Witwer KW, Aikawa E, Alcaraz MJ, Anderson JD, Andriantsitohaina R, et al. Minimal Information for Studies of Extracellular Vesicles 2018 (MISEV2018): A Position Statement of the International Society for Extracellular Vesicles and Update of the more and more achievements on exosomes will be made and applied in ESCC clinical diagnosis and therapy soon.

\section{AUTHOR CONTRIBUTIONS}

Literature review and writing-original draft preparation: $\mathrm{ZZ}$ and SY. Writing-review and editing: AZ, XL, RF, and SZ. Supervision and funding acquisition: PL and GZ. All authors have read and agreed to the published version of the manuscript.

\section{FUNDING}

This research was funded by the National Natural Science Foundation of China (no. 82070575), Beijing Natural Science Foundation (J180010), and Beijing Municipal Science \& Technology Commission (Z191100006619080).

\section{ACKNOWLEDGMENTS}

Many important contributions could not be cited due to space constraints, and we apologize to our colleagues for any relevant exclusion. The figures in this manuscript were created with BioRender.com.

MISEV2014 Guidelines. J Extracell Vesicles (2018) 7(1):1535750. doi: 10.1080/20013078.2018.1535750

9. Witwer KW, Thery C. Extracellular Vesicles or Exosomes? On Primacy, Precision, and Popularity Influencing a Choice of Nomenclature. J Extracell Vesicles (2019) 8(1):1648167. doi: 10.1080/20013078.2019.1648167

10. Pegtel DM, Gould SJ. Exosomes. Annu Rev Biochem (2019) 88:487-514. doi: 10.1146/annurev-biochem-013118-111902

11. Kalluri R, LeBleu VS. The Biology, Function, and Biomedical Applications of Exosomes. Science (2020) 367(6478):eaau6977. doi: 10.1126/science.aau6977

12. Sullivan R, Saez F, Girouard J, Frenette G. Role of Exosomes in Sperm Maturation During the Transit Along the Male Reproductive Tract. Blood Cells Mol Dis (2005) 35(1):1-10. doi: 10.1016/j.bcmd.2005.03.005

13. Xiao J, Pan Y, Li XH, Yang XY, Feng YL, Tan HH, et al. Cardiac Progenitor Cell-Derived Exosomes Prevent Cardiomyocytes Apoptosis Through Exosomal miR-21 by Targeting PDCD4. Cell Death Dis (2016) 7(6):e2277. doi: $10.1038 /$ cddis.2016.181

14. Rajagopal C, Harikumar KB. The Origin and Functions of Exosomes in Cancer. Front Oncol (2018) 8:66. doi: 10.3389/fonc.2018.00066

15. Chennakrishnaiah S, Meehan B, D'Asti E, Montermini L, Lee TH, Karatzas $\mathrm{N}$, et al. Leukocytes as a Reservoir of Circulating Oncogenic DNA and Regulatory Targets of Tumor-Derived Extracellular Vesicles. J Thromb Haemost (2018) 16(9):1800-13. doi: 10.1111/jth.14222

16. Kurywchak P, Tavormina J, Kalluri R. The Emerging Roles of Exosomes in the Modulation of Immune Responses in Cancer. Genome Med (2018) 10 (1):23. doi: 10.1186/s13073-018-0535-4

17. Babaei M, Rezaie J. Application of Stem Cell-Derived Exosomes in Ischemic Diseases: Opportunity and Limitations. J Transl Med (2021) 19(1):196. doi: 10.1186/s12967-021-02863-w

18. Xavier CPR, Caires HR, Barbosa MAG, Bergantim R, Guimaraes JE, Vasconcelos MH. The Role of Extracellular Vesicles in the Hallmarks of Cancer and Drug Resistance. Cells (2020) 9(5):1141. doi: 10.3390/cells9051141

19. Barile L, Vassalli G. Exosomes: Therapy Delivery Tools and Biomarkers of Diseases. Pharmacol Ther (2017) 174:63-78. doi: 10.1016/j.pharmthera.2017.02.020 
20. Wang M, Ji S, Shao G, Zhang J, Zhao K, Wang Z, et al. Effect of Exosome Biomarkers for Diagnosis and Prognosis of Breast Cancer Patients. Clin Transl Oncol (2018) 20(7):906-11. doi: 10.1007/s12094-017-1805-0

21. Wang H, Lu Z, Zhao X. Tumorigenesis, Diagnosis, and Therapeutic Potential of Exosomes in Liver Cancer. J Hematol Oncol (2019) 12(1):133. doi: 10.1186/s13045-019-0806-6

22. Soung YH, Ford S, Zhang V, Chung J. Exosomes in Cancer Diagnostics. Cancers (Basel) (2017) 9(1):8. doi: 10.3390/cancers9010008

23. Huang T, Deng CX. Current Progresses of Exosomes as Cancer Diagnostic and Prognostic Biomarkers. Int J Biol Sci (2019) 15(1):1-11. doi: 10.7150/ ijbs. 27796

24. Katakowski M, Buller B, Zheng X, Lu Y, Rogers T, Osobamiro O, et al. Exosomes From Marrow Stromal Cells Expressing miR-146b Inhibit Glioma Growth. Cancer Lett (2013) 335(1):201-4. doi: 10.1016/j.canlet.2013.02.019

25. Gehrmann U, Naslund TI, Hiltbrunner S, Larssen P, Gabrielsson S. Harnessing the Exosome-Induced Immune Response for Cancer Immunotherapy. Semin Cancer Biol (2014) 28:58-67. doi: 10.1016/ j.semcancer.2014.05.003

26. Samanta S, Rajasingh S, Drosos N, Zhou Z, Dawn B, Rajasingh J. Exosomes: New Molecular Targets of Diseases. Acta Pharmacol Sin (2018) 39(4):50113. doi: 10.1038/aps.2017.162

27. Wu P, Zhang B, Ocansey DKW, Xu W, Qian H. Extracellular Vesicles: A Bright Star of Nanomedicine. Biomaterials (2021) 269:120467. doi: 10.1016/ j.biomaterials.2020.120467

28. You DG, Lim GT, Kwon S, Um W, Oh BH, Song SH, et al. Metabolically Engineered Stem Cell-Derived Exosomes to Regulate Macrophage Heterogeneity in Rheumatoid Arthritis. Sci Adv (2021) 7(23):eabe0083. doi: $10.1126 /$ sciadv.abe 0083

29. Pan S, Zhang Y, Huang M, Deng Z, Zhang A, Pei L, et al. Urinary ExosomesBased Engineered Nanovectors for Homologously Targeted ChemoChemodynamic Prostate Cancer Therapy via Abrogating EGFR/AKT/NF$\mathrm{Kb} / \mathrm{IkB}$ Signaling. Biomaterials (2021) 275:120946. doi: 10.1016/ j.biomaterials.2021.120946

30. Cheng L, Zhang X, Tang J, Lv Q, Liu J. Gene-Engineered ExosomesThermosensitive Liposomes Hybrid Nanovesicles by the Blockade of CD47 Signal for Combined Photothermal Therapy and Cancer Immunotherapy. Biomaterials (2021) 275:120964. doi: 10.1016/j.biomaterials.2021.120964

31. Kalluri R. The Biology and Function of Exosomes in Cancer. J Clin Invest (2016) 126(4):1208-15. doi: 10.1172/JCI81135

32. van Niel G, D'Angelo G, Raposo G. Shedding Light on the Cell Biology of Extracellular Vesicles. Nat Rev Mol Cell Biol (2018) 19(4):213-28. doi: $10.1038 / \mathrm{nrm} .2017 .125$

33. McAndrews KM, Kalluri R. Mechanisms Associated With Biogenesis of Exosomes in Cancer. Mol Cancer (2019) 18(1):52. doi: 10.1186/s12943-0190963-9

34. Mathieu M, Martin-Jaular L, Lavieu G, Thery C. Specificities of Secretion and Uptake of Exosomes and Other Extracellular Vesicles for Cell-to-Cell Communication. Nat Cell Biol (2019) 21(1):9-17. doi: 10.1038/s41556-0180250-9

35. Willms E, Cabanas C, Mager I, Wood MJA, Vader P. Extracellular Vesicle Heterogeneity: Subpopulations, Isolation Techniques, and Diverse Functions in Cancer Progression. Front Immunol (2018) 9:738. doi: 10.3389 /fimmu. 2018.00738

36. Hessvik NP, Llorente A. Current Knowledge on Exosome Biogenesis and Release. Cell Mol Life Sci (2018) 75(2):193-208. doi: 10.1007/s00018-0172595-9

37. Kahlert C, Kalluri R. Exosomes in Tumor Microenvironment Influence Cancer Progression and Metastasis. J Mol Med (Berl) (2013) 91(4):431-7. doi: 10.1007/s00109-013-1020-6

38. Villarroya-Beltri C, Baixauli F, Gutierrez-Vazquez C, Sanchez-Madrid F, Mittelbrunn M. Sorting It Out: Regulation of Exosome Loading. Semin Cancer Biol (2014) 28:3-13. doi: 10.1016/j.semcancer.2014.04.009

39. Spencer N, Yeruva L. Role of Bacterial Infections in Extracellular Vesicles Release and Impact on Immune Response. BioMed J (2021) 44(2):157-64. doi: 10.1016/j.bj.2020.05.006

40. Yanez-Mo M, Siljander PR, Andreu Z, Zavec AB, Borras FE, Buzas EI, et al. Biological Properties of Extracellular Vesicles and Their Physiological Functions. J Extracell Vesicles (2015) 4:27066. doi: 10.3402/jev.v4.27066
41. Maia J, Caja S, Strano Moraes MC, Couto N, Costa-Silva B. Exosome-Based Cell-Cell Communication in the Tumor Microenvironment. Front Cell Dev Biol (2018) 6:18. doi: 10.3389/fcell.2018.00018

42. Gurung S, Perocheau D, Touramanidou L, Baruteau J. The Exosome Journey: From Biogenesis to Uptake and Intracellular Signalling. Cell Commun Signal (2021) 19(1):47. doi: 10.1186/s12964-021-00730-1

43. Tkach M, Kowal J, Zucchetti AE, Enserink L, Jouve M, Lankar D, et al. Qualitative Differences in T-Cell Activation by Dendritic Cell-Derived Extracellular Vesicle Subtypes. EMBO J (2017) 36(20):3012-28. doi: 10.15252/ embj.201696003

44. Sobo-Vujanovic A, Munich S, Vujanovic NL. Dendritic-Cell Exosomes Cross-Present Toll-Like Receptor-Ligands and Activate Bystander Dendritic Cells. Cell Immunol (2014) 289(1-2):119-27. doi: 10.1016/ j.cellimm.2014.03.016

45. Prada I, Meldolesi J. Binding and Fusion of Extracellular Vesicles to the Plasma Membrane of Their Cell Targets. Int J Mol Sci (2016) 17(8):1296. doi: 10.3390/ijms17081296

46. Yoon JH, Ashktorab H, Smoot DT, Nam SW, Hur H, Park WS. Uptake and Tumor-Suppressive Pathways of Exosome-Associated GKN1 Protein in Gastric Epithelial Cells. Gastric Cancer (2020) 23(5):848-62. doi: 10.1007/ s10120-020-01068-2

47. Horibe S, Tanahashi T, Kawauchi S, Murakami Y, Rikitake Y. Mechanism of Recipient Cell-Dependent Differences in Exosome Uptake. BMC Cancer (2018) 18(1):47. doi: 10.1186/s12885-017-3958-1

48. Eguchi S, Takefuji M, Sakaguchi T, Ishihama S, Mori Y, Tsuda T, et al. Cardiomyocytes Capture Stem Cell-Derived, Anti-Apoptotic microRNA214 via Clathrin-Mediated Endocytosis in Acute Myocardial Infarction. J Biol Chem (2019) 294(31):11665-74. doi: 10.1074/jbc.RA119.007537

49. Antimisiaris SG, Mourtas S, Marazioti A. Exosomes and Exosome-Inspired Vesicles for Targeted Drug Delivery. Pharmaceutics (2018) 10(4):218. doi: 10.3390/pharmaceutics10040218

50. He C, Li L, Wang L, Meng W, Hao Y, Zhu G. Exosome-Mediated Cellular Crosstalk Within the Tumor Microenvironment Upon Irradiation. Cancer Biol Med (2021) 18(1):21-33. doi: 10.20892/j.issn.2095-3941.2020.0150

51. Yang E, Wang X, Gong Z, Yu M, Wu H, Zhang D. Exosome-Mediated Metabolic Reprogramming: The Emerging Role in Tumor Microenvironment Remodeling and Its Influence on Cancer Progression. Signal Transduct Target Ther (2020) 5(1):242. doi: 10.1038/s41392-02000359-5

52. Qu L, Ding J, Chen C, Wu ZJ, Liu B, Gao Y, et al. Exosome-Transmitted lncARSR Promotes Sunitinib Resistance in Renal Cancer by Acting as a Competing Endogenous RNA. Cancer Cell (2016) 29(5):653-68. doi: $10.1016 /$ j.ccell.2016.03.004

53. Plebanek MP, Angeloni NL, Vinokour E, Li J, Henkin A, Martinez-Marin D, et al. Pre-Metastatic Cancer Exosomes Induce Immune Surveillance by Patrolling Monocytes at the Metastatic Niche. Nat Commun (2017) 8 (1):1319. doi: 10.1038/s41467-017-01433-3

54. Lee HY, Chen CK, Ho CM, Lee SS, Chang CY, Chen KJ, et al. EIF3CEnhanced Exosome Secretion Promotes Angiogenesis and Tumorigenesis of Human Hepatocellular Carcinoma. Oncotarget (2018) 9(17):13193-205. doi: 10.18632/oncotarget.24149

55. Stefanius K, Servage K, de Souza Santos M, Gray HF, Toombs JE, Chimalapati S, et al. Human Pancreatic Cancer Cell Exosomes, But Not Human Normal Cell Exosomes, Act as an Initiator in Cell Transformation. Elife (2019) 8:e40226. doi: 10.7554/eLife.40226

56. Zeng Q, Zhu Z, Song L, He Z. Transferred by Exosomes-Derived MiR-19b$3 p$ Targets PTEN to Regulate Esophageal Cancer Cell Apoptosis, Migration and Invasion. Biosci Rep (2020) 40(11):BSR20201858. doi: 10.1042/ BSR20201858

57. Gao DC, Hou B, Zhou D, Liu QX, Zhang K, Lu X, et al. Tumor-Derived Exosomal miR-103a-2-5p Facilitates Esophageal Squamous Cell Carcinoma Cell Proliferation and Migration. Eur Rev Med Pharmacol Sci (2020) 24 (11):6097-110. doi: 10.26355/eurrev_202006_21505

58. Gao P, Wang D, Liu M, Chen S, Yang Z, Zhang J, et al. DNA MethylationMediated Repression of Exosomal miR-652-5p Expression Promotes Oesophageal Squamous Cell Carcinoma Aggressiveness by Targeting PARG and VEGF Pathways. PloS Genet (2020) 16(4):e1008592. doi: 10.1371/journal.pgen.1008592 
59. Liao J, Liu R, Yin L, Pu Y. Expression Profiling of Exosomal miRNAs Derived From Human Esophageal Cancer Cells by Solexa High-Throughput Sequencing. Int J Mol Sci (2014) 15(9):15530-51. doi: 10.3390/ijms150915530

60. Zhuang H, Wang H, Yang H, Li H. Exosome-Encapsulated MicroRNA-21 From Esophageal Squamous Cell Carcinoma Cells Enhances Angiogenesis of Human Umbilical Venous Endothelial Cells by Targeting Spry1. Cancer Manag Res (2020) 12:10651-67. doi: 10.2147/CMAR.S259077

61. Yang YC, Liu GJ, Yuan DF, Li CQ, Xue M, Chen LJ. Influence of ExosomeDerived miR-21on Chemotherapy Resistance of Esophageal Cancer. Eur Rev Med Pharmacol Sci (2019) 23(4):1513-9. doi: 10.26355/eurrev_201902_17109

62. He Z, Li W, Zheng T, Liu D, Zhao S. Human Umbilical Cord Mesenchymal Stem Cells-Derived Exosomes Deliver microRNA-375 to Downregulate ENAH and Thus Retard Esophageal Squamous Cell Carcinoma Progression. J Exp Clin Cancer Res (2020) 39(1):140. doi: 10.1186/s13046020-01631-w

63. Shi S, Huang X, Ma X, Zhu X, Zhang Q. Research of the Mechanism on Mirna193 in Exosomes Promotes Cisplatin Resistance in Esophageal Cancer Cells. PloS One (2020) 15(5):e0225290. doi: 10.1371/journal.pone.0225290

64. Luo A, Zhou X, Shi X, Zhao Y, Men Y, Chang X, et al. Exosome-Derived miR-339-5p Mediates Radiosensitivity by Targeting Cdc25A in Locally Advanced Esophageal Squamous Cell Carcinoma. Oncogene (2019) 38 (25):4990-5006. doi: 10.1038/s41388-019-0771-0

65. Li W, Zhang L, Guo B, Deng J, Wu S, Li F, et al. Exosomal FMR1-AS1 Facilitates Maintaining Cancer Stem-Like Cell Dynamic Equilibrium via TLR7/NFkappaB/c-Myc Signaling in Female Esophageal Carcinoma. Mol Cancer (2019) 18(1):22. doi: 10.1186/s12943-019-0949-7

66. Li Z, Qin X, Bian W, Li Y, Shan B, Yao Z, et al. Exosomal lncRNA ZFAS1 Regulates Esophageal Squamous Cell Carcinoma Cell Proliferation, Invasion, Migration and Apoptosis via microRNA-124/STAT3 Axis. J Exp Clin Cancer Res (2019) 38(1):477. doi: 10.1186/s13046-019-1473-8

67. Zhang C, Luo Y, Cao J, Wang X, Miao Z, Shao G. Exosomal lncRNA FAM225A Accelerates Esophageal Squamous Cell Carcinoma Progression and Angiogenesis via Sponging miR-206 to Upregulate NETO2 and FOXP1 Expression. Cancer Med (2020) 9(22):8600-11. doi: 10.1002/cam4.3463

68. Zhu Z, Wang H, Pang Y, Hu H, Zhang H, Wang W. Exosomal Long nonCoding RNA UCA1 Functions as Growth Inhibitor in Esophageal Cancer. Aging (Albany NY) (2020) 12(20):20523-39. doi: 10.18632/aging.103911

69. Kang M, Ren M, Li Y, Fu Y, Deng M, Li C. Exosome-Mediated Transfer of IncRNA PART1 Induces Gefitinib Resistance in Esophageal Squamous Cell Carcinoma via Functioning as a Competing Endogenous RNA. J Exp Clin Cancer Res (2018) 37(1):171. doi: 10.1186/s13046-018-0845-9

70. Tong Y, Yang L, Yu C, Zhu W, Zhou X, Xiong Y, et al. Tumor-Secreted Exosomal lncRNA POU3F3 Promotes Cisplatin Resistance in ESCC by Inducing Fibroblast Differentiation Into CAFs. Mol Ther Oncolytics (2020) 18:1-13. doi: 10.1016/j.omto.2020.05.014

71. Lu Q, Wang X, Zhu J, Fei X, Chen H, Li C. Hypoxic Tumor-Derived Exosomal Circ0048117 Facilitates M2 Macrophage Polarization Acting as miR-140 Sponge in Esophageal Squamous Cell Carcinoma. Onco Targets Ther (2020) 13:11883-97. doi: 10.2147/OTT.S284192

72. Zhao G, Li H, Guo Q, Zhou A, Wang X, Li P, et al. Exosomal Sonic Hedgehog Derived From Cancer-Associated Fibroblasts Promotes Proliferation and Migration of Esophageal Squamous Cell Carcinoma. Cancer Med (2020) 9(7):2500-13. doi: 10.1002/cam4.2873

73. Yuan Y, Wang L, Ge D, Tan L, Cao B, Fan H, et al. Exosomal O-GlcNAc Transferase From Esophageal Carcinoma Stem Cell Promotes Cancer Immunosuppression Through Up-Regulation of PD-1 in CD8(+) T Cells. Cancer Lett (2021) 500:98-106. doi: 10.1016/j.canlet.2020.12.012

74. Li B, Song TN, Wang FR, Yin C, Li Z, Lin JP, et al. Tumor-Derived Exosomal HMGB1 Promotes Esophageal Squamous Cell Carcinoma Progression Through Inducing PD1(+) TAM Expansion. Oncogenesis (2019) 8(3):17. doi: $10.1038 / s 41389-019-0126-2$

75. Takeshima H, Ushijima T. Accumulation of Genetic and Epigenetic Alterations in Normal Cells and Cancer Risk. NPJ Precis Oncol (2019) 3:7. doi: 10.1038/s41698-019-0079-0

76. Baghban R, Roshangar L, Jahanban-Esfahlan R, Seidi K, Ebrahimi-Kalan A, Jaymand $\mathrm{M}$, et al. Tumor Microenvironment Complexity and Therapeutic Implications at a Glance. Cell Commun Signal (2020) 18(1):59. doi: 10.1186/ s12964-020-0530-4
77. Hamidi H, Ivaska J. Every Step of the Way: Integrins in Cancer Progression and Metastasis. Nat Rev Cancer (2018) 18(9):533-48. doi: 10.1038/s41568018-0038-z

78. Di Virgilio F, Sarti AC, Falzoni S, De Marchi E, Adinolfi E. Extracellular ATP and P2 Purinergic Signalling in the Tumour Microenvironment. Nat Rev Cancer (2018) 18(10):601-18. doi: 10.1038/s41568-018-0037-0

79. Finicle BT, Jayashankar V, Edinger AL. Nutrient Scavenging in Cancer. Nat Rev Cancer (2018) 18(10):619-33. doi: 10.1038/s41568-018-0048-x

80. Gurunathan S, Kang MH. Kim JH. A Comprehensive Review on Factors Influences Biogenesis, Functions, Therapeutic and Clinical Implications of Exosomes. Int J Nanomed (2021) 16:1281-312. doi: 10.2147/IJN.S291956

81. Matsumoto Y, Kano M, Murakami K, Toyozumi T, Suito H, Takahashi M, et al. Tumor-Derived Exosomes Influence the Cell Cycle and Cell Migration of Human Esophageal Cancer Cell Lines. Cancer Sci (2020) 111(12):434858. doi: $10.1111 /$ cas.14660

82. Paduch R. The Role of Lymphangiogenesis and Angiogenesis in Tumor Metastasis. Cell Oncol (Dordr) (2016) 39(5):397-410. doi: 10.1007/s13402016-0281-9

83. Ludwig N, Whiteside TL. Potential Roles of Tumor-Derived Exosomes in Angiogenesis. Expert Opin Ther Targets (2018) 22(5):409-17. doi: 10.1080/ 14728222.2018 .1464141

84. Wang Z, Dabrosin C, Yin X, Fuster MM, Arreola A, Rathmell WK, et al. Broad Targeting of Angiogenesis for Cancer Prevention and Therapy. Semin Cancer Biol (2015) 35 Suppl:S224-S43. doi: 10.1016/j.semcancer.2015.01.001

85. Olejarz W, Kubiak-Tomaszewska G, Chrzanowska A, Lorenc T. Exosomes in Angiogenesis and Anti-Angiogenic Therapy in Cancers. Int J Mol Sci (2020) 21(16):5840. doi: 10.3390/ijms21165840

86. Mao Y, Wang Y, Dong L, Zhang Y, Zhang Y, Wang C, et al. Hypoxic Exosomes Facilitate Angiogenesis and Metastasis in Esophageal Squamous Cell Carcinoma Through Altering the Phenotype and Transcriptome of Endothelial Cells. J Exp Clin Cancer Res (2019) 38(1):389. doi: 10.1186/ s13046-019-1384-8

87. Guan X. Cancer Metastases: Challenges and Opportunities. Acta Pharm Sin B (2015) 5(5):402-18. doi: 10.1016/j.apsb.2015.07.005

88. Ganesh K, Massague J. Targeting Metastatic Cancer. Nat Med (2021) 27 (1):34-44. doi: 10.1038/s41591-020-01195-4

89. Lambert AW, Weinberg RA. Linking EMT Programmes to Normal and Neoplastic Epithelial Stem Cells. Nat Rev Cancer (2021) 21(5):325-38. doi: 10.1038/s41568-021-00332-6

90. Wortzel I, Dror S, Kenific CM, Lyden D. Exosome-Mediated Metastasis: Communication From a Distance. Dev Cell (2019) 49(3):347-60. doi: 10.1016/j.devcel.2019.04.011

91. Wu X, Xiao S, Zhang M, Yang L, Zhong J, Li B, et al. A Novel Protein Encoded by Circular SMO RNA Is Essential for Hedgehog Signaling Activation and Glioblastoma Tumorigenicity. Genome Biol (2021) 22 (1):33. doi: 10.1186/s13059-020-02250-6

92. Shi X, Zhang Z, Zhan X, Cao M, Satoh T, Akira S, et al. An Epigenetic Switch Induced by Shh Signalling Regulates Gene Activation During Development and Medulloblastoma Growth. Nat Commun (2014) 5:5425. doi: 10.1038/ ncomms 6425

93. Min H, Sun X, Yang X, Zhu H, Liu J, Wang Y, et al. Exosomes Derived From Irradiated Esophageal Carcinoma-Infiltrating T Cells Promote Metastasis by Inducing the Epithelial-Mesenchymal Transition in Esophageal Cancer Cells. Pathol Oncol Res (2018) 24(1):11-8. doi: 10.1007/s12253-016-0185-Z

94. Wang M, Zhao X, Huang F, Wang L, Huang J, Gong Z, et al. Exosomal Proteins: Key Players Mediating Premetastatic Niche Formation and Clinical Implications (Review). Int J Oncol (2021) 58(4):4. doi: 10.3892/ijo.2021.5184

95. Shaheen O, Ghibour A, Alsaid B. Esophageal Cancer Metastases to Unexpected Sites: A Systematic Review. Gastroenterol Res Pract (2017) 2017:1657310. doi: 10.1155/2017/1657310

96. Gonzalez H, Hagerling C, Werb Z. Roles of the Immune System in Cancer: From Tumor Initiation to Metastatic Progression. Genes Dev (2018) 32(1920):1267-84. doi: 10.1101/gad.314617.118

97. Ozga AJ, Chow MT, Luster AD. Chemokines and the Immune Response to Cancer. Immunity (2021) 54(5):859-74. doi: 10.1016/j.immuni.2021.01.012

98. Syn NL, Teng MWL, Mok TSK, Soo RA. De-Novo and Acquired Resistance to Immune Checkpoint Targeting. Lancet Oncol (2017) 18(12):e731-e41. doi: 10.1016/S1470-2045(17)30607-1 
99. Mao Y, Wang Y, Dong L, Zhang Q, Wang C, Zhang Y, et al. Circulating Exosomes From Esophageal Squamous Cell Carcinoma Mediate the Generation of B10 and PD-1(High) Breg Cells. Cancer Sci (2019) 110 (9):2700-10. doi: 10.1111/cas.14122

100. Goodman KA, Ou FS, Hall NC, Bekaii-Saab T, Fruth B, Twohy E, et al. Randomized Phase II Study of PET Response-Adapted Combined Modality Therapy for Esophageal Cancer: Mature Results of the CALGB 80803 (Alliance) Trial. J Clin Oncol (2021) JCO2003611. doi: 10.1200/ JCO.20.03611

101. Hulshof M, Geijsen ED, Rozema T, Oppedijk V, Buijsen J, Neelis KJ, et al. Randomized Study on Dose Escalation in Definitive Chemoradiation for Patients With Locally Advanced Esophageal Cancer (ARTDECO Study). J Clin Oncol (2021) JCO2003697. doi: 10.1200/JCO.20.03697

102. Li S, Yi M, Dong B, Jiao Y, Luo S, Wu K. The Roles of Exosomes in Cancer Drug Resistance and Its Therapeutic Application. Clin Transl Med (2020) 10 (8):e257. doi: $10.1002 / \mathrm{ctm} 2.257$

103. Jella KK, Rani S, O’Driscoll L, McClean B, Byrne HJ, Lyng FM. Exosomes Are Involved in Mediating Radiation Induced Bystander Signaling in Human Keratinocyte Cells. Radiat Res (2014) 181(2):138-45. doi: 10.1667/RR13337.1

104. Liang H, Fan JH, Qiao YL. Epidemiology, Etiology, and Prevention of Esophageal Squamous Cell Carcinoma in China. Cancer Biol Med (2017) 14(1):33-41. doi: 10.20892/j.issn.2095-3941.2016.0093

105. Global Burden of Disease Cancer C, Fitzmaurice C, Allen C, Barber RM, Barregard L, Bhutta ZA, et al. Global, Regional, and National Cancer Incidence, Mortality, Years of Life Lost, Years Lived With Disability, and Disability-Adjusted Life-Years for 32 Cancer Groups, 1990 to 2015: A Systematic Analysis for the Global Burden of Disease Study. JAMA Oncol (2017) 3(4):524-48. doi: 10.1001/jamaoncol.2016.5688

106. Mannath J, Ragunath K. Role of Endoscopy in Early Oesophageal Cancer. Nat Rev Gastroenterol Hepatol (2016) 13(12):720-30. doi: 10.1038/ nrgastro.2016.148

107. Chen X, Gole J, Gore A, He Q, Lu M, Min J, et al. Non-Invasive Early Detection of Cancer Four Years Before Conventional Diagnosis Using a Blood Test. Nat Commun (2020) 11(1):3475. doi: 10.1038/s41467-020-17316-Z

108. Grady WM, Yu M, Markowitz SD. Epigenetic Alterations in the Gastrointestinal Tract: Current and Emerging Use for Biomarkers of Cancer. Gastroenterology (2021) 160(3):690-709. doi: 10.1053/j.gastro.2020.09.058

109. Mori MA, Ludwig RG, Garcia-Martin R, Brandao BB, Kahn CR. Extracellular miRNAs: From Biomarkers to Mediators of Physiology and Disease. Cell Metab (2019) 30(4):656-73. doi: 10.1016/j.cmet.2019.07.011

110. O’Brien K, Breyne K, Ughetto S, Laurent LC, Breakefield XO. RNA Delivery by Extracellular Vesicles in Mammalian Cells and Its Applications. Nat Rev Mol Cell Biol (2020) 21(10):585-606. doi: 10.1038/s41580-020-0251-y

111. Thietart S, Rautou PE. Extracellular Vesicles as Biomarkers in Liver Diseases: A Clinician's Point of View. J Hepatol (2020) 73(6):1507-25. doi: 10.1016/ j.jhep.2020.07.014

112. van der Pol Y, Mouliere F. Toward the Early Detection of Cancer by Decoding the Epigenetic and Environmental Fingerprints of Cell-Free DNA. Cancer Cell (2019) 36(4):350-68. doi: 10.1016/j.ccell.2019.09.003

113. Hoshino A, Kim HS, Bojmar L, Gyan KE, Cioffi M, Hernandez J, et al. Extracellular Vesicle and Particle Biomarkers Define Multiple Human Cancers. Cell (2020) 182(4):1044-61.e18. doi: 10.1016/j.cell.2020.07.009

114. Thind A, Wilson C. Exosomal miRNAs as Cancer Biomarkers and Therapeutic Targets. J Extracell Vesicles (2016) 5:31292. doi: 10.3402/ jev.v5.31292

115. Salehi M, Sharifi M. Exosomal miRNAs as Novel Cancer Biomarkers: Challenges and Opportunities. J Cell Physiol (2018) 233(9):6370-80. doi: $10.1002 /$ jcp. 26481

116. Fitts CA, Ji N, Li Y, Tan C. Exploiting Exosomes in Cancer Liquid Biopsies and Drug Delivery. Adv Healthc Mater (2019) 8(6):e1801268. doi: 10.1002/ adhm.201801268

117. Tanaka Y, Kamohara H, Kinoshita K, Kurashige J, Ishimoto T, Iwatsuki M, et al. Clinical Impact of Serum Exosomal microRNA-21 as a Clinical Biomarker in Human Esophageal Squamous Cell Carcinoma. Cancer (2013) 119(6):1159-67. doi: 10.1002/cncr.27895

118. Qiu ML, Li X, Lin JB, Luo RG, Liu B, Feng Z. Serum Exosomal miR-182 Upregulation Predicts Unfavorable Prognosis of Esophageal Squamous Cell
Carcinoma. Eur Rev Med Pharmacol Sci (2020) 24(10):5412-8. doi: 10.26355/eurrev_202005_21325

119. Liu S, Lin Z, Zheng Z, Rao W, Lin Y, Chen H, et al. Serum Exosomal microRNA-766-3p Expression Is Associated With Poor Prognosis of Esophageal Squamous Cell Carcinoma. Cancer Sci (2020) 111(10):3881-92. doi: $10.1111 /$ cas. 14550

120. Liu S, Lin Z, Rao W, Zheng J, Xie Q, Lin Y, et al. Upregulated Expression of Serum Exosomal Hsa_Circ_0026611 Is Associated With Lymph Node Metastasis and Poor Prognosis of Esophageal Squamous Cell Carcinoma. J Cancer (2021) 12(3):918-26. doi: 10.7150/jca.50548

121. Ni PZ, He JZ, Wu ZY, Ji X, Chen LQ, Xu XE, et al. Overexpression of Stathmin 1 Correlates With Poor Prognosis and Promotes Cell Migration and Proliferation in Oesophageal Squamous Cell Carcinoma. Oncol Rep (2017) 38(6):3608-18. doi: 10.3892/or.2017.6039

122. Ma HL, Jin SF, Ju WT, Fu Y, Tu YY, Wang LZ, et al. Stathmin Is Overexpressed and Regulated by Mutant P53 in Oral Squamous Cell Carcinoma. J Exp Clin Cancer Res (2017) 36(1):109. doi: 10.1186/s13046017-0575-4

123. Rong B, Nan Y, Liu H, Gao W. Increased Stathmin Correlates With Advanced Stage and Poor Survival of Non-Small Cell Lung Cancer. Cancer Biomark (2017) 19(1):35-43. doi: 10.3233/CBM-160239

124. Li M, Yang J, Zhou W, Ren Y, Wang X, Chen H, et al. Activation of an AKT/ FOXM1/STMN1 Pathway Drives Resistance to Tyrosine Kinase Inhibitors in Lung Cancer. Br J Cancer (2017) 117(7):974-83. doi: 10.1038/bjc.2017.292

125. Yan L, Dong X, Gao J, Liu F, Zhou L, Sun Y, et al. A Novel Rapid Quantitative Method Reveals Stathmin-1 as a Promising Marker for Esophageal Squamous Cell Carcinoma. Cancer Med (2018) 7(5):1802-13. doi: 10.1002/cam4.1449

126. Liu MX, Liao J, Xie M, Gao ZK, Wang XH, Zhang Y, et al. miR-93-5p Transferred by Exosomes Promotes the Proliferation of Esophageal Cancer Cells via Intercellular Communication by Targeting PTEN. BioMed Environ Sci (2018) 31(3):171-85. doi: 10.3967/bes2018.023

127. Liu T, Du LT, Wang YS, Gao SY, Li J, Li PL, et al. Development of a Novel Serum Exosomal MicroRNA Nomogram for the Preoperative Prediction of Lymph Node Metastasis in Esophageal Squamous Cell Carcinoma. Front Oncol (2020) 10:573501. doi: 10.3389/fonc.2020.573501

128. Tian L, Yang L, Zheng W, Hu Y, Ding P, Wang Z, et al. RNA Sequencing of Exosomes Revealed Differentially Expressed Long Noncoding RNAs in Early-Stage Esophageal Squamous Cell Carcinoma and Benign Esophagitis. Epigenomics (2020) 12(6):525-41. doi: 10.2217/epi-2019-0371

129. Jiao Z, Yu A, Rong W, He X, Zen K, Shi M, et al. Five-lncRNA Signature in Plasma Exosomes Serves as Diagnostic Biomarker for Esophageal Squamous Cell Carcinoma. Aging (Albany NY) (2020) 12(14):15002-10. doi: 10.18632/ aging.103559

130. Yan S, Du L, Jiang X, Duan W, Li J, Xie Y, et al. Evaluation of Serum Exosomal lncRNAs as Diagnostic and Prognostic Biomarkers for Esophageal Squamous Cell Carcinoma. Cancer Manag Res (2020) 12:9753-63. doi: 10.2147/CMAR.S250971

131. Fan L, Cao Q, Liu J, Zhang J, Li B. Circular RNA Profiling and Its Potential for Esophageal Squamous Cell Cancer Diagnosis and Prognosis. Mol Cancer (2019) 18(1):16. doi: 10.1186/s12943-018-0936-4

132. Lin Y, Dong H, Deng W, Lin W, Li K, Xiong X, et al. Evaluation of Salivary Exosomal Chimeric GOLM1-NAA35 RNA as a Potential Biomarker in Esophageal Carcinoma. Clin Cancer Res (2019) 25(10):3035-45. doi: 10.1158/1078-0432.CCR-18-3169

133. Ding Z, Yan Y, Guo YL, Wang C. Esophageal Carcinoma Cell-Excreted Exosomal Uc.189 Promotes Lymphatic Metastasis. Aging (Albany NY) (2021) 13(10):13846-58. doi: 10.18632/aging.202979

134. Tikhomirov R, Donnell BR, Catapano F, Faggian G, Gorelik J, Martelli F, et al. Exosomes: From Potential Culprits to New Therapeutic Promise in the Setting of Cardiac Fibrosis. Cells (2020) 9(3):592. doi: 10.3390/cells9030592

135. Dang XTT, Kavishka JM, Zhang DX, Pirisinu M, Le MTN. Extracellular Vesicles as an Efficient and Versatile System for Drug Delivery. Cells (2020) 9 (10):2191. doi: 10.3390/cells9102191

136. Shao J, Zaro J, Shen Y. Advances in Exosome-Based Drug Delivery and Tumor Targeting: From Tissue Distribution to Intracellular Fate. Int J Nanomed (2020) 15:9355-71. doi: 10.2147/IJN.S281890 
137. Ha D, Yang N, Nadithe V. Exosomes as Therapeutic Drug Carriers and Delivery Vehicles Across Biological Membranes: Current Perspectives and Future Challenges. Acta Pharm Sin B (2016) 6(4):287-96. doi: 10.1016/j.apsb.2016.02.001

138. Liao W, Du Y, Zhang C, Pan F, Yao Y, Zhang T, et al. Exosomes: The Next Generation of Endogenous Nanomaterials for Advanced Drug Delivery and Therapy. Acta Biomater (2019) 86:1-14. doi: 10.1016/j.actbio.2018.12.045

139. Bari E, Ferrarotti I, Di Silvestre D, Grisoli P, Barzon V, Balderacchi A, et al. Adipose Mesenchymal Extracellular Vesicles as Alpha-1-Antitrypsin Physiological Delivery Systems for Lung Regeneration. Cells (2019) 8 (9):965. doi: 10.3390/cells8090965

140. Ullah M, Liu DD, Rai S, Razavi M, Choi J, Wang J, et al. A Novel Approach to Deliver Therapeutic Extracellular Vesicles Directly Into the Mouse Kidney via Its Arterial Blood Supply. Cells (2020) 9(4):937. doi: 10.3390/cells9040937

141. Matsumura S, Minamisawa T, Suga K, Kishita H, Akagi T, Ichiki T, et al. Subtypes of Tumour Cell-Derived Small Extracellular Vesicles Having Differently Externalized Phosphatidylserine. J Extracell Vesicles (2019) 8 (1):1579541. doi: 10.1080/20013078.2019.1579541

142. Ding L, Yang X, Gao Z, Effah CY, Zhang X, Wu Y, et al. A Holistic Review of the State-Of-the-Art Microfluidics for Exosome Separation: An Overview of the Current Status, Existing Obstacles, and Future Outlook. Small (2021) 17 (29):e2007174. doi: 10.1002/smll.202007174

143. Meng W, He C, Hao Y, Wang L, Li L, Zhu G. Prospects and Challenges of Extracellular Vesicle-Based Drug Delivery System: Considering Cell Source. Drug Delivery (2020) 27(1):585-98. doi: 10.1080/10717544.2020.1748758

144. Samal S, Dash P, Dash M. Drug Delivery to the Bone Microenvironment Mediated by Exosomes: An Axiom or Enigma. Int J Nanomed (2021) 16:3509-40. doi: 10.2147/IJN.S307843

145. Chen L, Hong W, Ren W, Xu T, Qian Z, He Z. Recent Progress in Targeted Delivery Vectors Based on Biomimetic Nanoparticles. Signal Transduct Target Ther (2021) 6(1):225. doi: 10.1038/s41392-021-00631-2
146. Go G, Lee J, Choi DS, Kim SS, Gho YS. Extracellular Vesicle-Mimetic Ghost Nanovesicles for Delivering Anti-Inflammatory Drugs to Mitigate GramNegative Bacterial Outer Membrane Vesicle-Induced Systemic Inflammatory Response Syndrome. Adv Healthc Mater (2019) 8(4): e1801082. doi: 10.1002/adhm.201801082

147. Gao X, Ran N, Dong X, Zuo B, Yang R, Zhou Q, et al. Anchor Peptide Captures, Targets, and Loads Exosomes of Diverse Origins for Diagnostics and Therapy. Sci Transl Med (2018) 10(444):eaat0195. doi: 10.1126/scitranslmed.aat0195

148. Kamerkar S, LeBleu VS, Sugimoto H, Yang S, Ruivo CF, Melo SA, et al. Exosomes Facilitate Therapeutic Targeting of Oncogenic KRAS in Pancreatic Cancer. Nature (2017) 546(7659):498-503. doi: 10.1038/nature22341

Conflict of Interest: The authors declare that the research was conducted in the absence of any commercial or financial relationships that could be construed as a potential conflict of interest.

Publisher's Note: All claims expressed in this article are solely those of the authors and do not necessarily represent those of their affiliated organizations, or those of the publisher, the editors and the reviewers. Any product that may be evaluated in this article, or claim that may be made by its manufacturer, is not guaranteed or endorsed by the publisher.

Copyright (c) 2021 Zhao, Yang, Zhou, Li, Fang, Zhang, Zhao and Li. This is an openaccess article distributed under the terms of the Creative Commons Attribution License (CC BY). The use, distribution or reproduction in other forums is permitted, provided the original author(s) and the copyright owner(s) are credited and that the original publication in this journal is cited, in accordance with accepted academic practice. No use, distribution or reproduction is permitted which does not comply with these terms. 